\title{
OVERALL QUALITY CONTROL OF 1:10000 ORTHOPHOTO PRODUCTS IN THE THIRD NATIONAL LAND SURVEY
}

\author{
Qing-qing Yan ${ }^{1-}$, You-song Zhao ${ }^{1}$, Chang $\mathrm{Liu}^{1}, \mathrm{Xu} \mathrm{Ma}^{1}$, Xuan WU \\ ${ }^{1}$ National Quality Inspection and Testing Center for Surveying and Mapping Products,Beijing,China - 476175217@qq.com
}

KEYWORDS: The third national land survey;1:10000 Orthophoto products; Overall inspection; Quality control;key nodes; Key quality subelements ;Image quality

\begin{abstract}
Orthographic image is an important reference data source for the third national land survey, as well as the positioning benchmark and statistical basis of the national land survey, which determines the accuracy of the third national land survey results and the progress of follow-up work, and is also an important component of the third national land survey results. In order to ensure that the production of 1:10000 high-resolution orthophoto images meets the needs of the third national land survey work, and meets the relative requirements to the production of orthophoto products, it is really necessary to carry out quality control of orthophoto products.Based on the checking and accepting of 1:10000 orthophoto images at the national level, this paper discusses the quality control method of 1:10000 orthophoto products from the overall inspection.First of all, this paper studies and analyzes the key nodes of quality control in the overall inspection and clarifies the quality control requirements of each quality control key node;On the basis of carefully sorting out the typical problems found in the overall inspection of orthophoto products, carry out in-depth analysis of the causes and give corresponding solutions. This paper provides a technical reference for the quality inspection of other scale orthophoto products, and also provides a solution to the quality improvement of 1:10000 orthophoto products.
\end{abstract}

Corresponding author-Qing-qing Yan,476175217@qq.com,+8615210869448 


\section{INTRODUCTION}

Land survey is an important legal system in our country and an important means to check and clarify land resources in an all-round way. The third national land survey, as a major national situation and national strength survey, is based on orthophoto map. Through field investigation of land type, area and ownership, it carries out detailed investigation of cultivated land and inefficient idle land, and establish an interconnected and shared land survey database that integrates image, land, scope, area and ownership at the national, provincial, prefecture and county levels. It is of great significance for implementing the most stringent farmland protection system and the most stringent land-saving system, improving the precision level of land and resources management, and supporting and promoting sustainable economic and social development. High resolution remote sensing orthographic image is an important reference data source for the third national land survey, as well as the positioning benchmark and statistical basis of the national land survey, which determines the accuracy of the third national land survey results and the progress of follow-up work, and is also an important component of the third national land survey results. Only by providing the orthophoto products that meet the quality requirements can we meet the needs of the survey and ensure the correctness and reliability of the national land survey. Therefore, the quality control of the orthophoto products is very necessary.

The inspection and acceptance of 1:10000 orthophoto products in the third national land survey adopted the method of combining the overall inspection outside the sample with the detailed inspection of the sample. In order to control the quality of 1:10000 orthophoto Products outside the sample, This paper studies and analyzes the key nodes of quality control in the overall inspection and clarifies the quality control requirements of each quality control key node; On the basis of carefully sorting out the typical problems found in the overall inspection of orthophoto products, carry out in-depth analysis of the causes and give corresponding solutions. This paper provides a technical reference for the quality inspection of other scale orthophoto products, and also provides a solution to the quality improvement of 1:10000 orthophoto products.

\section{QUALITY CONTROL KEY NODES FOR OVERALL} SURVEY

In this paper, the quality control of orthophoto products is carried out from the key quality subelements such as spatial reference system, logic consistency, image quality and attachment quality.

\subsection{Spatial Reference System}

Check the correctness of the parameters defined in the coordinate system to ensure that the coordinate system of the orthophoto products is consistent with the coordinate system of the land survey products; Check the correctness of the Gauss projection zone, the central meridian and the zone number to ensure that the Orthophoto products and land survey products can be overlaped.

\subsection{Logic Consistency}

Check the correctness of data file storage organization to ensure the establishment of 1:10000 orthophoto database of national land survey products; Check the correctness of data file format to ensure the uniformity of data file format in China; Check the integrity and readability of data files to ensure the integrity and readability of data submissions; Check the correctness of the name and extension of the data file to ensure that the county, batch, data source, resolution and year information of the image product can be obtained quickly according to the file name.

\subsection{Image Quality}

The overall inspection of the quality of orthophoto products mainly includes the following contents:

(1)Check the valid data range of orthophoto outward expansion, the Minimum Enclosing Rectangle of county range and the correctness of the data area without data area assignment, so as to ensure that the orthophoto product covers the whole county and can be seamlessly stitched between different counties.

(2)Check the correctness of RGB color mode of orthophoto product to ensure the correctness of color display. 
(3)Check whether there are color anomalies in the fusion processing of orthophoto prpducts, and whether there are texture blurring, contour blurring, faintness, duplication and grain sensation of important objects; Whether there are distortions in important objects; Check whether there are cracks and loopholes in the image results; Whether there are large areas of clouds, snow, fog and shadows covering important object, or serious overexposure, commercial services, industrial and mining warehousing, housing, public management and public services, transportation, waters and water conservancy facilities are not affect.

\subsection{Attachment Quality}

Check whether metadata file organization and county tessera information file organization meet the requirements; Check the correctness of the coordinate system of metadata and county tessera information file to ensure that metadata, tessera information file and orthophoto products can be correctly integrated; Check the correctness and readability of metadata and county tessera information file data format to ensure that data content can be read smoothly; Check the correctness of the name of metadata file and county tessera information file, the conformity of file storage organization and file integrity to ensure that the county image results can be matched quickly.

\section{PROBLEMS FOUND IN OVERALL SURVEY AND CAUSE ANALYSIS}

\subsection{Spatial Reference System}

There are undefined projections in the orthophoto products, and there are also cases that the projections are not defined according to the specifications such as no code added before the projection information. This will lead to the orthophoto products incompatible with the land survey vector data and county tessera information files. Therefore, it is impossible to compare and analyze the orthophoto products as the base map of land survey, and to obtain the information of data source, data source phase, incidence angle, resolution, sampling interval and so on. This problem can be solved by software automated inspection.

\subsection{Logic Consistency}

Lost files when submitting orthophoto products, such as missing projection information files, orthophoto naming errors, metadata naming errors, etc.. Therefore, the orthophoto products cannot be smoothly imported into the database and cannot be easily searched by users quickly.

During and after the orthophoto production, some data files were lost due to the operators' failure to timely sort out the data files according to the submission requirements or their failure to earnestly study the requirements of relevant documents.

\subsection{Image Quality}

The main quality problems in the general overview of orthographic image results are as follows:

(1)The valid data range of the submitted data results is incorrect. For example, there is a data vulnerability area in the image results.

Because of the strip loophole in the original image, the Orthophoto products was not enlarged to a certain scale when they were made, so the loophole was not found, or the different scene images were not stitched in mosaic splicing. This needs to be supplemented by other images.

(2)The RGB values of the area pixels between the tangent of the effective data range of the image result and the minimum circumscribed rectangle are not set correctly. There is a problem that the RGB values of pixels are all NoData or the individual values are NoData. This can assign the place of NoData to 0 by using a conditional query function.

(3)There are serious color anomalies after image fusion processing, which affect the interpretation of cultivated land, forest land, garden land, grassland, transportation land and other ground features.

Because the original image color has some problems such as unclear gradation, deviation between color and actual ground objects or unclear definition of ground objects, color processing is required. Improper color processing will lead to abnormal color of local images. This requires the image color processing to be carried out according to the sequence of first adjusting the definition, then adjusting the levels and colors to increase the 
image color, so that it does not affect the interpretation of land survey contents such as cultivated land, garden land, forest land, grassland, commercial clothing, industrial and mining storage, residence, public management and public service, transportation, water area and water conservancy facilities land, etc.

(4)The distortion of important objects such as roads and bridges seriously affects the sample precision of important objects.

The DEM used in image rectification process is usually close to the ground. The actual elevation of road and bridge is not consistent with DEM data. In the process of image rectification by software, the software itself can not judge where is the road and where is the bridge. Therefore, erroneous rectification will occur, resulting in distortion important objects such as overpass, expressways and newly built houses. The DEM can be manually modified locally and then the image can be modified; If the distortion of the ground object is small and the connection with the surrounding ground object is good, the original image can be used to supplement the surrounding ground object.

(4)Excessive exposure of Orthophoto products seriously affects the interpretation of features.

Due to exposure of the original image or the large contrast between the brightness and contrast of the original image, some local ground objects become too bright or too dark, or even become pure white or pure black, after the data is homogenized. The interpretation of land survey contents such as cultivated land, garden land, woodland, grassland, commercial clothing, industrial and mining warehousing, housing, public management and public service, transportation, water fish and chicken water conservancy facilities land, etc., which are seriously affected by the original image problems, needs to be partially supplemented by other original images.

\subsection{Attachment Quality}

Due to the inadequate technical training, the operators did not set up the correct coordinate system of mosaic information file correctly, did not submit mosaic information file completly, and did not named metadata and mosaic information file correctly.

\section{CONCLUSION}

The third national land survey is based on the newly satellite remote sensing image or aerial image, which has a direct impact on the accuracy of the land survey results, thus indirectly affecting the credibility of information management of land and resources. Starting from the key quality subelements of quality control affecting 1:10000 Orthophoto products, combined with the main quality problems, this paper analyses the causes of quality problems, and puts forward relevant solutions. In this paper, the quality control of the 1:10000 Orthophoto products of the third national land survey is carried out from the overall inspection, which has certain technical support and guiding significance for the production of high-quality Orthophoto products.

\section{REFERENCES}

Xi-wei L, Li-xia Z, Shuang Z. A Brief Analysis of Manual Inspection Method of the Orthophoto Quality Control of the Third National Land Survey[J]. Survey World, 2018.

Erxin Y, Liguo W, Aigong X, et al. Exploratory on the orthography production for the 3 th national land survey_-Take Jingtai County as an example[J]. Mine Surveying, 2018.

Li-Xia Z , Yan-Li C , Shuang Z . Simple Discussion the Checking of Standard Time Approval of the Geographic Conditions Census Project Digital Ortho Image[J]. Geomatics \& Spatial Information Technology, 2015.

Qiu-Ying J , Ke-Xue Z, Rong Z . Method and Technique of Adjusting Color for Digital Orthophoto Map[J]. Coal Technology, 2007.

Hai-zhong.Z. Data Production and Quality Control of Digital Orthophoto Mapping (DOM) in Geographic Conditions Census[J].Water Resources \& Hydropower of Northeast China, 2014.

Chun fang H. A Practical Method for Improving the Quality of Orthophoto Maps[J]. GEOSPAYIAL INFORMATION 2014.8. 
The International Archives of the Photogrammetry, Remote Sensing and Spatial Information Sciences, Volume XLII-3/W10, 2020 International Conference on Geomatics in the Big Data Era (ICGBD), 15-17 November 2019, Guilin, Guangxi, China

De-xi W, Chun-peng M. Influence of Quality Factors on Geographical Condition Survey Orthophoto Map Production[J]. GEOMATICS \& SPATIAL INFORMATION TECHNOLOGY, 2014. 